\title{
THE FISH IN THE CREEK IS SENTIENT, EVEN IF I CAN'T SPEAK WITH IT
}

\author{
Michael L. Woodruff ${ }^{1}$
}

\begin{abstract}
In this paper I argue that Velmens' reflexive model of perceptual consciousness is useful for understanding the first-person perspective and sentience in animals. I then offer a defense of the proposal that ray-finned bony fish have a first-person perspective and sentience. This defense has two prongs. The first prong is presence of a substantial body of evidence that the neuroanatomy of the fish brain exhibits basic organizational principles associated with consciousness in mammals. These principles include a relationship between a second-order sensory relay, the preglomerular complex, and the fish pallium which bears a resemblance to the relationship between the mammalian thalamus and the neocortex, the existence of feedback/feedforward and reentrant circuitry in the pallium, and structural and functional differences among divisions of the fish pallium. The second prong is the existence of behaviors in fish that exhibit significant flexibility in the presence of environmental change and require relational learning among stimuli distributed in space, over time, or both. I conclude that, although they are instantiated differently, a first-person perspective and sentience are present in fish.
\end{abstract}

Key Words: Sentience. Fish. Behavior. Pallium. Reflexive monism.

\section{INTRODUCTION}

The fish in the creek said nothing. Fish never do. Few people know what fish think about injustice, or anything else. (Ursula K. Le Guin, Catwings).

They are old questions, the questions associated with consciousness. Perhaps the most fundamental of these questions is whether consciousness should even be considered a part of the ontology. In answer to this question some scholars say no. They propose that consciousness is "nothing more" than patterns of neural activity and can, even must, be eliminated from the ontology. (CHURCHLAND, 1981; CHURCHLAND, 1986; CRICK,

\footnotetext{
${ }^{1}$ Professor, East Tennessee State University, Johnson City, TN - United States of America. E-mail: mlwoodruff1@gmail.com
}

http://dx.doi.org/10.1590/0101-3173.2018.v41esp.08.p119

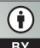

This is an open-access article distributed under the terms of the Creative Commons Attribution License. 
1994; DENNETT, 1991; LEWIS, 1980; SMART, 1959). On this view, the contents of consciousness have no causal powers. At best they are epiphenomena. Others disagree. They argue that this treatment is too sparse (PRICE; BARRELL, 2012; SEARLE, 2000; SPERRY, 1991; VELMANS, 2009; WIMSATT, 1976) and insist that consciousness is an ontologically real entity with causal powers that cannot be reduced to the activity of neural circuitry.

My subjective experience compels me to accept this latter position. I cannot deny that I perceive red, enjoy a favorite tune, wonder if it will be cold tomorrow, and believe drinking water will alleviate my thirst. Furthermore, such conscious intentional states strongly contribute to producing my behavioral actions even if they are not the sole cause. I stop at a red light. I pick up my mandolin and play a tune I like. I plan to get out my topcoat tomorrow morning if it is cold. I seek and drink water when I am thirsty. Like Descartes, I know that I exist because I have conscious thoughts. Indeed, I agree with Lynne Rudder Baker: to deny the ontological reality of consciousness is to commit "cognitive suicide" (BAKER, 1988).

So, I answer "yes" to the fundamental question presented at the beginning of the last paragraph. The evidence I presented to support my answer came from the subjective experience of my own states of consciousness, that is, from the first-person point-of-view. Realistically I must use evidence from my first-person perspective to infer by analogy from, for example, verbal descriptions by other humans that they also have states of consciousness. This inference may provide a sufficiently strong foundation for rejection of outright solipsism, but is it strong enough to support theories of consciousness?

If crucial criteria for these theories are that they are empirically testable and potentially falsifiable the answer to this question may be no. Meeting these criteria requires scientific investigation which requires the ability to make third-person observations. Consciousness is not accessible to the third-person perspective. Therefore, so the argument concludes, consciousness cannot be investigated scientifically (BAKER, 2013; LEVINE, 1983; NAGEL, 1986). This conclusion implies that an empirically-based epistemology of consciousness is beyond reach, an implication that is especially detrimental to attempts to explain the relationship between consciousness and the entities and activities of the brain upon which, by most accounts, it depends (GENNARO; FISHMAN, 2015). This is the case because of the seemingly insurmountable differences between the properties of consciousness derived 
from the first-person point of view and the properties of the brain established from the third person point of view. The situation presents a conundrum which, if it cannot be solved, allows even substance dualism as a possible, if not plausible, theoretical option.

\section{POINT OF VIEW AND THE SCIENTIFIC INVESTIGATION OF CONSCIOUSNESS}

I will suggest some answers to this apparent conundrum. The third person point of view is prized in science because it is assumed that, due to its public nature, observations made from it are objective. That is, they are free from the influence of individual and sociocultural presuppositions and, therefore, provide reliable and valid data about reality. The first-person point of view, by definition, is subjective. Therefore, it is assumed to be very susceptible to such presuppositions. Each of these assumptions has been challenged.

Thomas Kuhn offered a strong challenge to the assumption that thirdperson observations made by scientists are free from subjective influences. In his influential book The Structure of Scientific Revolutions Kuhn (1970) argued that, apart from a rare revolution that causes a paradigm shift, scientific research is governed by defined paradigms. On Kuhn's view a paradigm is far more than a theoretical commitment. A paradigm is a way of looking at the world that includes conceptual, theoretical, instrumental and methodological commitments. These commitments constrain not just the hypotheses a scientist constructs, but importantly, the observations she makes and how she is able to interpret those observations.

Following Kuhn, then, it is frequently acknowledged by philosophers of science (DOUGLAS, 2009; HAACK, 2007; HARKER, 2015) that, because observers are often influenced by sociocultural values inherent in scientific paradigms, their third-person point of view is not completely objective. This is not to say that the third person point of view is not central and essential to the success of the scientific approach. Even accepting that subjective values intrude into scientific decision-making, scientific investigation drives technological advancement and provides the most accurate information for formation of public policy (BIRCH, 2017; DOUGLAS, 2009; HARKER, 2015; WOODRUFF, 2017b). However, it is to say that the privileged position of the third-person point of view in scientific research vis-à-vis the first-person point of view must be questioned. 
This proposal is not novel. For example, beginning from a different metaphysical position, Velmans $(2007,2009,2012)$ agrees with the stance I just took on the absolute objectivity of the third-person point of view. As Velmans (2007, p. 419) succinctly puts it "one cannot make observations without engaging the experiences and cognitions of a conscious subject (unobserved meter readings are not "observations"). If so Science cannot be "objective" in the sense of being observer-free."

Velmans $(2007,2009,2012)$ also presents a cogent argument for the corollary to this proposal. That is, the first-person point of view must be included with the third-person point of view in a legitimate science of consciousness. His reflexive model of perceptual consciousness is integral to his argument. The following situation adapted from Velmans (2007, 2012) illustrates the reflexive model. A subject $(S)$ looks at an illuminated light in a dimly lit room. She reports her experience of the light to an experimenter (E). Additionally, the electroencephalographic (EEG) activity of S's brain is recorded both in the absence and the presence of the light. Changes in the EEG recorded from S's brain can be correlated with the content of verbal reports $S$ provides about her experience of the light.

So, what makes this situation reflexive? The energy emitted by the illuminated light is associated with specific changes in S's visual system as reflected in EEG patterns in her brain. It is reasonable to assume that this brain activity is essential for $S$ to perceive the light, but she does not perceive the light as located in her brain. Phenomenologically she experiences its location projected out into the environment. Velmans (2012, p. 146) summarizes the situation as follows.

Physical processes initiated within a light bulb out in the world, once they are processed by the subject's visual system, are perceived as a light out in the world located more or less where the initiating processes are. That is what makes the entire process reflexive (the entire sequence loops back on itself). Similar reflexive loops typically apply to events initiated within the body, at the body surface or within the brain itself.

In addition to using this situation to illustrate his reflexive model, Velmans uses it to argue that subjective experience and brain electrical activity are both intrinsic to consciousness. He demands that both must be included in any complete explanation of consciousness. But this demand returns us to the conundrum I described at the end of the first section of this article. How 
can the incompatible natures of consciousness and the brain be reconciled? Velmans' answer to this question is that the dualism apparent here is due to the divergent ways conscious experience and the brain must be known. S's experience of the light can only be known from her first-person point of view, while her EEG can only be known from the third person point of view. He postulates one underlying entity that connects the two forms of knowledge and that is S's mind. Thus, he (VELMANS, 2012, p. 151) maintains epistemological dualism, but avoids ontological substance and property dualism, proposing instead an ontological theory of mind he calls reflexive monism.

Hence, Velmans legitimizes the first-person point of view as a source of evidence in scientific investigation of the mind. However, the private nature of this evidence must be overcome before this evidence can be used in construction and evaluation of hypotheses about consciousness. That is, individuals must be able to make their experiences public through accurate report. Fortunately, it is generally acknowledged that humans can provide such accurate reports. These reports are often verbal, but nonverbal behavioral responses may also be used, and, particularly when procedures adapted from psychophysics are used, they yield both qualitative and quantitative information that is demonstrably reliable and valid (HAYNES et al., 2005; PRICE; BARRELL, 2012). These reports can also be used to identify neural correlates of conscious experience (BOLY et al., 2017; DEHAENE, 2014; HAYNES et al., 2005; KOCH, 2012).

\section{POINTS OF VIEW AND CONSCIOUSNESS IN FISH: DEFINITIONS}

I began this paper by stating that questions about consciousness are old questions. I then argued that for human consciousness Velmans' reflexive monism can resolve some of these questions. Reflexive monism may also be useful in answering another old question about consciousness: to what extent is it found among the branches of the phylogenetic tree. In the remainder of this paper I will address this question for the branches of this tree occupied by the species belonging to teleost subclass of the class Actinopterygii, commonly known as ray-finned fishes (hereinafter referred to as fish). I chose fish as my subject matter because this subclass seems to be at the line of disputation regarding the phylogenetic extent of consciousness. Some philosophers and scientists adamantly deny that fish are capable of consciousness (CARRUTHERS, 1989; KEY 2015, 2016; KEY et al., 2017; 
ROSE, 2002, 2007; ROSE et al., 2014). Others adamantly insist that fish are conscious (ANDREWS, 2015; BRAITHEWAITE, 2010; BROWN, 2014; 2017; SNEDDON, 2015; SNEDDON et al., 2018). In agreement with the latter group and my previous publications (WOODRUFF 2017a, 2018) I will argue in the remainder of this paper that behavioral and neurological evidence supports the contention that fish are sentient beings with a firstperson point of view.

To begin, however, it must be recognized that, as Kristin Andrews (2015, p. 4) states: "Members of the human species have human minds, and if members of other species have minds, they will have species-specific minds of their own." The same must be said about consciousness. Yet, it is virtually inevitable that we turn to philosophical and psychological theories of human consciousness as reference points when we attribute consciousness to animals (EDELMAN et al., 2005; EDELMAN; SETH, 2009; SETH et al., 2005). It also seems necessary to turn to theories that relate human neuroanatomy and neurophysiology to consciousness as reference points for evaluating possible neurobiological substrates of consciousness in animals (BOLY et al., 2013; EDELMAN et al., 2005; EDELMAN; SETH, 2009; ROSE et al., 2014; SETH et al., 2005). I will use these reference points in this paper in making my arguments that fish are sentient. The forms of my arguments are common to philosophical and scientific theories of animal minds and include the argument from analogy, the argument from evolutionary parsimony, and inference to the best explanation (ANDREWS, 2015, p. 9-12).

So, I will use the approach just outlined to argue that fish are sentient. But what does it mean to be sentient? As a general answer to this question I view sentience as a form of phenomenal consciousness and distinguish it from access consciousness (BLOCK, 1995). ${ }^{2}$ Specifically, adapted from Allen and Trestman (2016) I propose that sentience in fish includes the ability to have subjective experience of the phenomenological/qualitative properties associated with external and internal sensations. This ability is limited. It is similar to what Gerald Edelman $(1989,2003)$ called primary consciousness. He (EDELMAN, 2003, p. 5521) summarized an animal with primary consciousness in this way: "Such an animal with primary consciousness has no explicit narrative capability (although it has long-term memory), and, at best,

\footnotetext{
${ }^{2}$ Indeed, in agreement with others (BAARS; LAUREY, 2005) I have argued that access consciousness as a separate entity is a superfluous concept (WOODRUFF, 2018). Engagement of attention explains how the contents of phenomenal consciousness enter awareness.
} 
it can only plan to deal with the immediate scene in the remembered present. Nonetheless, it has an advantage over an animal lacking such an ability to plan." This seems a heuristically useful description of the function of sentience in fishes.

Additionally, in agreement with Panksepp (2005), Damasio (2010) Feinberg and Mallatt (2016) and Pereira Jr. (2013, 2014) I advocate that the phenomenological/qualitative properties of sentience necessarily have an affective "feel" to them. In his paper in this volume Pereira Jr. (2018, p. 213) articulates this necessary connection very clearly writing: "Without Feeling, all we have is non-conscious mental processing, limited to the processing of afferent information, formation of representations and activation of motor control in response to environmental stimuli."

Thus, as it is defined here, first-order representational theories of consciousness (DRETSKE, 1995; TYE, 2000) would seem to adequately account for sentience. A higher order representational theory (ROSENTHAL, 2005), even as espoused by Gennaro (2004), is not required. However, although sentience does not require higher-order perceptions or thoughts about first-order mental states for its existence, it does require a first-person perspective from which phenomena are experienced. The nature of this firstperson perspective must be compatible with the definition of sentience. Bearing this caveat in mind, I think that Baker (2013) provided a plausible and useful general distinction between two manifestations of the first-person perspective - robust and rudimentary. On Baker's view, only humans can have a robust first-person perspective as it requires the capacity for language and the ability for self-consciousness. However, animals can have a rudimentary firstperson perspective as it requires neither linguistic ability nor self-consciousness. Possession of a rudimentary first-person perspective entails only that a subject is the origin in time and space of its perception of the environment.

I propose that Baker's rudimentary first-person perspective provides a ground from which a sentient being, in this case a fish, can experience the affective feels associated with the phenomenological/qualitative properties of external and internal sensations. However, in postulating the existence of a rudimentary first-person perspective Baker explicitly eschews any discussion of consciousness, but it seems necessary to specify some form of connection between sentience and the being that is sentient. I submit that Pereira Jr. (2018, p. 209) provides this connection with his concept of extended conscious domain. To quote from his paper in this volume: 
I propose the concept of an extended conscious domain (ECD), characterized by a lived experience or presentation that occurs in the "egocentric space", having the subjective point of view at its center, and the world of objects "out there" as the horizon (PEREIRA JR., 2018, p. 209).

ECD then extends the conscious domain out into the environment and supports the reflexive perceptual processes for organization of the external world proposed by Velmans. In the case of fish, the subjective point of view at the center of the egocentric space would correspond to the rudimentary firstperson point of view. While the rudimentary first-person point of view cannot support cognitive processes involving complex logic, language and so forth, it is adequate to support "non-conceptual conscious activities" (PEREIRA JR., 2018, p. 212), that is, it supports sentience. In the following sections I will continue arguments that I have made in previous papers (WOODRUFF, 2017a, 2018) and present evidence that fish exhibit behaviors indicative of the presence of a rudimentary first-person perspective, ECD and sentience as well as the neurobiological complexity necessary to support these processes.

\section{IDENTIFYING SENTIENCE IN FISH: SOME CAVEATS}

Before I present neurobiological and behavioral evidence for sentience in fish, I will mention some caveats. First, although arguments both for (WOODRUFF, 2017a) and against (KEY, 2015; ROSE, 2007; ROSE et al., 2014) the existence of sentience in fish inevitably use human brain neurobiology and behavior as a reference point, if fish have consciousness whatever form it takes will be unique to fish. Indeed, Nagel's (1974) point concerning bats certainly applies to fish. While it may be possible - and I contend that it is possible - to provide strong evidential support for the hypothesis that fish are sentient, that is fish have non-conceptual, feeling-laden subjective experience of external and internal sensations, it is not possible to portray what this subjective experience might be like. But it is like something. In sum, then, my argument is that the same recognition for sentience should be extended to fish as has been given to terrestrial vertebrates and even to octopi (ALLEN; TRESTMAN, 2015; CABANAC et al., 2009; EDELMAN et al., 2005; EDELMAN; SETH, 2009; KEY, 2015; SETH et al., 2005).

A second caveat has to do with the generalizability of the evidence I will present. I limit my discussion to ray-finned fishes. I do not include lobe-finned fishes (chondrichthyes), the other sub-class of bony fishes. I also 
exclude the cartilaginous fishes. This subclass includes the sharks, rays, skates, and sawfish (elasmobranchii) and the ghost shark (holocephali). However, this still leaves approximately 30,000 species of bony fish which have adapted to a myriad of ecological niches. The behavior of only a small percentage of these species has been systematically studied in the wild. The behavior of a smaller number of fish species has been subjected to controlled laboratory experiments and very few species of fish have been used for neuroanatomical and neurophysiological experiments. Yet, I continually refer to fish when I generalize my conclusions. It is fair to criticize this generalization as some have done (ALLEN-HERMANSON, 2017; ROSE et al., 2014). Ideally appropriate experimentation should decide generalizability and on a limited basis this has been done in fish. For example, goldfish exhibit trace conditioning (PORTAVELLA et al., 2004; VARGAS et al., 2009). Can this finding be generalized to other species of fish? Experiments have confirmed the presence of trace conditioning in cod and halibut (NILSSON et al., 2008, 2010), species which occupy a different ecological niche than goldfish. Cross species confirmation has also been found for other behaviors and several neurobiological findings (WOODRUFF, 2017b, 2018). Additionally, if direct experimental evidence is absent a theoretical model presented by Brown (2017) offers an evolutionarily defensible approach to generalizing behavioral evidence across species. I recognize the limitations of my evidence but defend the generalizability of my conclusions at least across the species cited in this paper.

I indicated above that it is common to use a theory explaining the relationship between the human brain and consciousness as the benchmark for evaluating possible neurobiological substrates of consciousness in animals (BOLY et al., 2013; EDELMAN et al., 2005; EDELMAN; SETH, 2009; ROSE et al., 2014; SETH et al., 2005). Indeed, employment of this benchmark seems inescapable, but this leads to a third caveat. There is no agreed-upon theory of how the brain causes consciousness, or even a consensus about what really constitute the neural correlates of consciousness (NCC). Recognizing this caveat, in what follows I discuss neuroanatomical structures and neurophysiological activities in fish that have been proposed by different scientists as NCCs in humans. If at least some of these NCCs are valid markers of consciousness in humans, then it is plausible that their presence in fish also indicates the existence of some form of consciousness in this subclass of animals. 
Egocentric SPATIAL INTEGRATION, THE OPTIC TECTUM, POINT OF VIEW AND SENTIENCE IN FISH

Although they call it by different names (core consciousness, sensory consciousness, primary consciousness) several authors (DAMASIO, 2010; FEINBERG; MALLATT, 2016; MERKER, 2007; PANSKEPP, 2005) have proposed that hindbrain, midbrain and diencephalic nuclei are all that is needed for sentience as defined in this paper. The optic tectum (OT) is central to most of these theories. In fish the OT (Figure 1A) is essential for sensorimotor integration. All sensory modalities present in any given teleost species, except olfaction, are represented in the optic tectum. These modalities include input from the lateral line system which detects movement and, in a few species, electrosenory input which complements the visual system in detecting objects in the environment. The ability of the OT to produce a topographic representation of the environment for each of the relevant sensory inputs and to integrate these inputs to produce directed, adaptive motor output provides general support for the theory that the OT and its connections provide the basis of sentience. The ability of fish to represent and remember spatial locations provides a specific example.

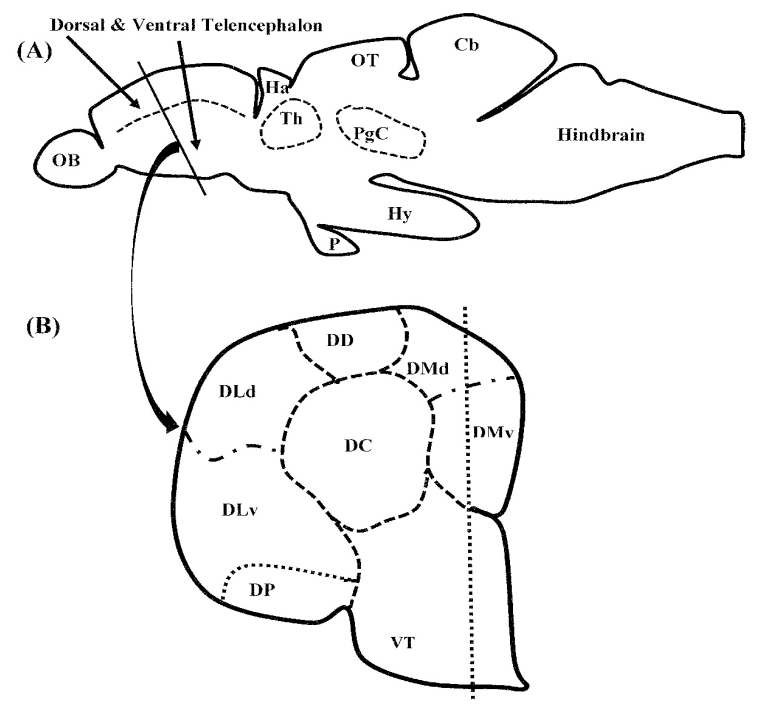


Figure 1: (A) Schematic of a longitudinal (sagittal) section of the fish brain. The drawing represents a parasagittal section from the location of the dashed line in (B). That is, it comes from a location slightly away from the midline of the brain. Abbreviations: $\mathrm{Cb}$ cerebellum; Ha - habenula; Hy -hypothalamus; OB - olfactory bulb; OT - optic tectum; Th - thalamus; P - pituitary; PgC - preglomerular complex; Th - thalamus. (B) A schematic cross section from the dorsal through the ventral surface of one hemisphere of the fish telencephalon. The section is drawn to represent the approximate anterior-posterior level of the brain demarcated by the vertical line in (A). It shows the locations of the pallial divisions given by Nieuwenhuys and Meek (1990). Abbreviations (all beginning with D refer to divisions of the pallium): DD - dorsodorsal; DMd - dorsomedial dorsalis); DLv (dorsomedial ventralis); DLd (dorsolateral dorsalis); DLv (dorsolateral ventralis); DC (doralis centralis); DP dorsalis posterior; VT (ventral \{subpallial\} telencephalon)

Survival for fish requires that they navigate their spatial environment effectively and remember places where prey have been found, predators lurk, and safety is available. Accurate representation of the spatial location of objects in the environment by the brain is required for successful navigation. Spatial representation is generally considered to come in two forms - egocentric or self-to-object and allocentric or object-to-object (Figure 2). Egocentric representation is specific to the current location of the subject making the response in relation to the location of the relevant object. For example, if the subject standing at Position 1 in Figure 2A uses egocentric spatial coding, the path to each object will depend on specific body responses unique to Position 1 (e. g. turn right toward the tree, move straight ahead toward the car). If the subject moves to Position 2 and only uses egocentric spatial memory, the old learned responses (turn right to go to the tree) will not create a path to the object. Different bodily responses would have to be learned through renewed exposure to each object in order to establish a pathway to it. 

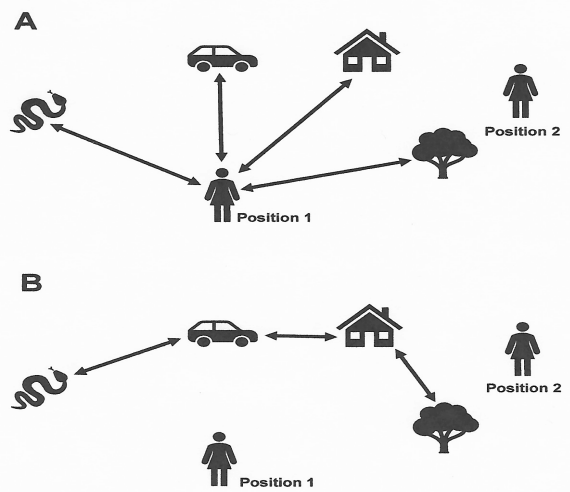

Figure 2: (A) Egocentric representation specifies the location of objects with respect to the subject's position (subject-centered representation indicated by the arrows). It is dependent on the subject's position in space and is fundamental to sensory control of motor action because successful execution of an object-directed action requires representation of the object's location in relationship to the subject. (B) Allocentric representation specifies object-to-object (arrows) spatial relationships (world-centered representation). It is independent of the subject's position in space and allows greater flexibility in navigating as the subject changes position over time. Successful navigation does not solely on either egocentric or allocentric representation but requires the ability to switch and combine spatial strategies as goals and the environment change.

The ability of an animal to use egocentric spatial information depends on the existence of topographic representations of the environment in the central nervous system. In fish topographic representation occurs first in the OT. The presence of egocentric representation in the OT is compatible, as the double ended arrows in Figure 2A suggest, with Velmans' reflexive model of perceptual consciousness. Egocentric representation in the fish OT is also compatible with the proposal that the OT is the first anatomical component of Pereira Jr.'s (2018, p. 209) extended conscious domain (ECD) and the 
rudimentary first-person perspective. On this view then, the presence of egocentric representation in the OT supports theories that make the OT an important component of the neurological basis of sentience.

\section{THE PREGLOMERULAR COMPLEX, THE PALLIUM, ALLOCENTRIC SPATIAL INTEGRATION, AND SENTIENCE IN FISH}

It is generally agreed that consciousness in humans (and other mammals) requires the neocortex, the thalamus and connections between the two (CRICK; KOCH, 2003; DEHAENE, 2014; EDELMAN et al., 2005; EDELMAN, 1989; KEY, 2015; LLINÀS et al., 1998). In particular, the sensory modality specific input from the thalamus to the cortex, the segregation of this sensory input in different cortical areas, and the rich interconnections among multiple cortical areas are proposed to be necessary for conscious appreciation of the defining qualitative phenomenal properties of sensory stimuli. Strict acceptance of these requirements for consciousness leads to rejection of any theory that proposes that brainstem structures are enough for sentience. This is the position taken by critics who argue that fish are not sentient (KEY, 2015, 2016; ROSE, 2002, 2007; ROSE et al., 2014). Their argument rests on the proposition that the fish pallium lacks the necessary complexity of structure and that the sensory input from the fish thalamus to the pallium lacks the topographic organization necessary to support any form of phenomenal consciousness.

However, it must be kept in mind that structure-function relationships change with changes in position on the phylogenetic tree. Functions that might require a neocortex as it is structured in mammals might not have this requirement in other classes of animal. For example, birds lack a neocortex, but it is generally granted that their hyperpallium supports some form of phenomenal consciousness (EDELMAN; SETH, 2009; EDELMAN et al., 2005; KARTEN, 2015). I emphasize this point because the results of research reviewed briefly below and extensively by Woodruff (2017a, 2018) indicates that the fish pallium has multiple functional divisions and these divisions have neuronal connections among them that create the feedforward, feedback, and reentrant circuitry associated with sentience in mammals. Furthermore, the conclusion that the fish lacks a structure that is functionally like the mammalian sensory thalamus seems unwarranted. The fish pallium does receive qualitatively specific sensory input, but this input 
comes from the preglomerular complex (PgC; Figure 1A) not the thalamus (refer to WOODRUFF, 2017a for original references). This pattern of connectivity between the PgC and the pallium led Ito and Yamamoto (2009, p. 117) to conclude that "ascending pathways mediated by the preglomerular complex enumerated above exhibit a considerable degree of modality-specific organization similarly to mammalian thalamocortical pathways" and Mueller (2012) to make the PgC a principle component of the "wider thalamus."

However, relevant questions arise. Do the $\mathrm{PgC}$, the pallium, and the connections between them add to capabilities already established in fish by the OT and its brainstem connections? If they do, how are these new capabilities related to sentience? To answer these questions, I will return to representation of spatial information in the fish brain and discuss allocentric representation and allocentric memory.

Allocentric processing refers to the ability of a subject to use and encode into memory spatial information based on the physical relationships of objects as part of a distant scene independent of the subject's position relative to those objects (Figure 2B). Hence, allocentric spatial memory contains a "cognitive map" of the environment which can be referred to regardless of whether the subject in Figure 2B is in Position 1, Position 2 or any other position from which objects in the map can be observed. Compared to egocentric spatial processing, allocentric processing allows greater flexibility in the guidance of navigation in animals that range freely across space.

Declarative memory in humans and other mammals is associated with consciousness and provides flexible guidance to behavior in different contexts (COHEN; POLDARK; EICHENBAUM, 1997; EICHENBAUM; COHEN, 2014). Allocentric spatial memory can be considered a form of declarative memory (EICHENBAUM, 2000; EICHENBAUM; COHEN, 2014) and has been included as one marker for consciousness (SETH et al., 2005). Allocentric spatial processing and allocentric memory have been found in a number of species of fish (BROWN, 2014; DURÀN et al., 2010; CRESON et al., 2003; WHITE; BROWN, 2015). As I argued in a previous paper (WOODRUFF, 2017a) the presence of allocentricity in fish is evidence that they have some form of declarative memory and, therefore, are sentient.

Egocentric spatial representation precedes allocentric spatial representation (BREMNER, 1978). It follows, then, that a brain process exists by which egocentric representation is transformed into allocentric 
representation. Rose (2007; ROSE et al., 2014) has argued that behaviors in fish offered as evidence for the existence of sentience lack construct validity unless the presence of sentience cannot be independently confirmed. He goes on to argue that construct validity could be gained if brain structures in fish could be shown to be related to consciousness in the same way that areas of the human brain (e.g. frontal cortex, parietal cortex, thalamus) can be shown to be related to behavioral markers of consciousness in humans. Following this line of argument, then, it would be useful to my argument if areas of the fish brain could be related to the transformation of egocentric spatial representation into allocentric spatial representation and to processing of allocentric memory.

A recent study by Wallach et al. (2018) indicates that at least in the weakly electric brown ghost knifefish (apteronotus leptorhynchus) this transformation occurs in the PgC. The electric brown ghost knifefish does use vision to sense objects in its environment, but it also detects distortions in the electric field it generates around itself when objects come near its body. Electrosensation is particularly useful in the murky waters knifefish often inhabit. Both visual input and electrosensory input produce topographic egocentric maps in the OT of the brown ghost knifefish. The PgC receives synaptic input from OT neurons and the topographic segregation of qualitatively different sensory modalities remains (GIASSI et al., 2012b; NORTHCUTT, 2006), but the $\mathrm{PgC}$ also modifies OT input in a way which is relevant to sentience.

Wallach et al. characterized the responses of neurons in the $\mathrm{PgC}$ to presentation of objects in their near environment. They found that the most frequent responses of $\mathrm{PgC}$ electrosensory neurons were to the beginning or ending of movement of novel objects, or to the introduction or removal of novel objects. That is, neuron response rates quickly decreased with sustained motion or continued presence of a stimulus object. They also recorded from a few visually responsive $\mathrm{PgC}$ neurons and found a similar pattern of response. These results indicate that, unlike neurons in the OT, some $\mathrm{PgC}$ neurons code temporal information, not just spatial information.

To control the parameters of stimulus presentation in this experiment the fish were immobilized, and the stimuli were moved, but the results can be extrapolated to moving fish and stationary objects. The inference can then be made that in a freely-swimming knifefish the egocentric coding found in the OT is lost in the PgC. Rather, the time between sequential encounters with individual novel objects as the fish swims is represented. The representation of time between encounters with external objects is an important element 
in deriving distance between objects in an allocentric representation of the environment. Two other necessary components for constructing an allocentric map are swim velocity and heading direction. In fish the lateral line system codes swim velocity (OTEIZA et al., 2017) and the vestibular system codes heading direction (STRAKA; BAKER, 2013. Both are represented in the PgC. Based on known input of electrosensory, visual, lateral line and vestibular information from the $\mathrm{PgC}$ to the $\mathrm{DL}$ pallium, as well as experimental studies done in other species of fish relating DL to spatial behavior, Wallach et al. (2018) propose that the DL is where allocentric space and allocentric memories are represented.

Wallach et al. (2018) also cite the homologous relationship between the fish DL and the mammalian hippocampus in support of their hypothesis. The mammalian hippocampus is associated allocentric spatial processing. For example, hippocampal neurons in rats show place-related increases in the firing rate and hippocampal lesions impair allocentric spatial learning (NADEL, 1991). While homology does not necessarily entail similar function, research indicates that in several species of non-electric fish the DL participates in allocentric representation. For example, Canfield and Mizumori (2004) found that that DL neurons in freely swimming cichlid fish and goldfish show place- and orientation-related increases in the firing rate. This activity of DL neurons in fish is reminiscent of the activity of hippocampal neurons in freely-moving rats (O'KEEFE; NADEL, 1978). Additionally, Uceda et al. (2015) and Ocaña et al. (2017) have observed spatial-learning-related increases in metabolic activity in the goldfish ventral DLv. A second source of evidence comes from reports that lesions of the entire DL (DURÁN et al., 2010; VARGAS et al., 2006), or just to the DLv (BINGMAN et al., 2017), impair allocentric spatial learning in goldfish. DM lesions, on the other hand, have no effect on allocentric spatial learning (DURÁN et al., 2010; VARGAS et al., 2006).

The functional relationships inferred from these experiments may not, however, be as straightforward as they appear. For example, while the hippocampus proper is important in allocentric spatial learning (NADEL, 1991), so are adjacent cortical areas, the parahippocampal and retrosplenial gyri (EKSTROM et al., 2014). These gyri connect with the anterior nucleus of the thalamus (AnTh), a structure which in mammals is associated with allocentric spatial learning (AGGLETON et al., 2010; JANKOWSKI et al., 2013). The mammalian hippocampus proper does not have direct connections 
with AnTh, but the fish DL does (ECHTELER; SAIDEL, 1981). Combined, these observations suggest that the DL may include anatomical and functional similarities to parts of the mammalian neocortex in addition to having functional analogy in spatial learning to the mammalian hippocampus proper.

\section{ADDITIONAL ANATOMICAL SUPPORT FOR THE HYPOTHESIS THAT FISH ARE SENTIENT}

The evidence presented above supports the hypothesis that fish are capable of allocentric representation and memory and, by implication, are sentient. Specific gross anatomical structures associated with generation of allocentric representations and memories have been identified. These are the OT, the PgC and the DL. Additionally, the intrinsic organization of the DL is complex enough for sophisticated representation of sensations, at least for the DL of the knifefish in which both neuronal layers and a detectable columnar organization has been observed (TRINH et al., 2015). Not only do vertical pallial neuronal columns exist in the knifefish, each column connects reciprocally to adjacent columns creating local recurrent networks throughout the DL (TRINH et al., 2015). It is important to emphasize here, as did Trinh et al., that the columns observed in knifefish are not structurally discrete in the same way as are columns in regions of the mammalian neocortex such as the somatosensory cortex. However, they do resemble the overlapping cryptic ocular dominance columns found in the visual cortex (KASKAN et al., 2007). Cryptic columnar organization allows small changes in input to one column to cause a slight shift in neuronal activity in overlapping columns, thereby allowing spatiotemporal integration of sensory input. This organization would seem to be quite appropriate for an area responsible for generation of cognitive maps of the spatial environment from multi-modal sensory input.

However, production of complex behaviors associated with sentience in fish requires more than just the neural circuitry intrinsic to the DL. Neuroanatomical differentiation among pallial and interconnections among these divisions is also required. These requirements have been met. Differentiation begins with qualitative differentiation of sensations within the pallium produced, as mentioned above, by segregation of modalityspecific sensory input from the $\mathrm{PgC}$ within the pallium. Axons from the $\mathrm{PgC}$ representing different sensations terminate in different pallial divisions or are topographically segregated within a single pallial division. For example, visual input terminates more heavily in the dorsal lateral pallium (DLd/DLv 
in Figure 1) than in the dorsomedial pallium (DM) and neuron clusters in different parts of the DM receive auditory, gustatory, and lateral line input (DEMSKI, 2013; PRECHTL et al., 2008).

However, sensory input does not dominate the connections of all pallial divisions. The primary inputs and outputs of the dorsodorsal pallium (DD, Fig. 1B) are reciprocal glutaminergic excitatory connections with the DL and DM. These connections create feedforward/feedback excitation between these pallial divisions and the DD. Furthermore, the dorsalis centralis of the pallium (DC, Fig. 1B) receives comparatively little subpallial input but has reciprocal glutaminergic excitatory connections with other pallial divisions, and is the major source of excitatory pallial output to the tectum, the $\mathrm{PgC}$, and numerous other subpallial sensory-motor structures all of which return excitatory input to the pallium (ECHTELER; SAIDEL, 1981; see WOODRUFF, 2017a, for a complete list of references). These three pallial regions, thus, have circuits that can support reentrant processing, one of the proposed requirements for a neurobiological substrate of sentience (CRICK; KOCH, 2003; EDELMAN, 1989, 2003).

While excitatory neurons are required for positive feedforward and feedback control of local circuits and reentrant processing, inhibitory neurons are necessary for temporal stabilization and spatial sharpening of activity within these circuits. Inhibitory GABAergic neuron cell bodies and terminals have been observed in the DL, DD, DM and DC in zebrafish and knifefish. The source of some of the GABAergic terminals is the telencephalic subpallium (VT in Figure 1B) which, in turn, receives excitatory glutaminergic input from the DM (GIASSI et al., 2012a). Whether the source is intrinsic or extrinsic, GABAergic terminals within the DL, DM and DD modulate the activity of excitatory glutaminergic neurons (VARGAS et al., 2012).

It should also be noted that the pallium of the fish receives subpallial input from nonspecific modulatory systems comprising cholinergic, dopaminergic, GABAergic, serotonergic, and noradrenergic neurons. The presence of dopaminergic and serotonergic input suggests that motivational and affectual systems found in mammals also exist in fishes, thereby enabling the feeling states I and others associate with sentience. It may also be the case that the DM pallium is directly involved in producing these feeling states (refer to WOODRUFF, 2017a, for original references). 


\section{NEUROPHYSIOLOGICAL CORRELATES OF SENTIENCE IN FISH}

In sum, then, many of the presumed neuroanatomical requirements for sentience that have been postulated for humans have been found, albeit in significantly modified form, in fish. For example, there is sensory segregation of input from the OT through the $\mathrm{PgC}$ to the pallium. The pallium has anatomically distinct regions with different functions and one of these regions even has a rudimentary columnar organization that resembles the cryptic columns found in the visual cortex in some mammals.

Compared to research on the neurophysiological correlates of consciousness in mammals, few neurophysiological experiments relevant to discovering possible correlates of sentience in fish can be found in the literature. However, electroencephalograms (EEG) taken from the skulls of three species of fish exhibit generalized electrophysiological responses correlated with several criteria of sentience in mammals. EEGs from Atlantic salmon (LAMBOOJI et al., 2010), African catfish (LAMBOOJI et al., 2006) and the turbot (LAMBOOJI et al., 2015) demonstrated that the fish brain generates electrical activity in the delta $(0.5-4 \mathrm{~Hz})$, theta $(4-8 \mathrm{~Hz})$, alpha $(8-14 \mathrm{~Hz})$, beta $(14-30 \mathrm{~Hz})$ and gamma $(30 \mathrm{~Hz}$ and higher) bandwidths. The same spectrum of EEG frequencies is generated by the mammalian cortex and correlates with levels of arousal and, at the gamma frequency, with attentional processes and possibly with sensory binding associated with consciousness (CRICK; KOCH, 2003; EDELMAN, 2003; ORPWOOD, 2013).

In addition to mammalian-like generalized neurophysiological responses, the teleost pallium shows modality-specific, sensory-evoked responses. Prechtl et al. (1998) recorded evoked action potentials from the pallial neurons of weakly electric elephant nose fish in response to auditory, visual, lateral line and electrical field stimulation. The electrical field stimulation was not noxious but mimicked stimulation produced as it moved by the fish itself. The results were compatible with the anatomical data described above. Responses to visual stimuli were observed predominantly in the LP. Responses to electrical stimulation were found in the lateral part of DM. Responses to lateral line and auditory stimuli were found primarily in DM. Finally, Prechtl et al. observed that each of the sensory stimuli caused field potentials that oscillated in bandwidths from 15 to $55 \mathrm{~Hz}$. The higher end of these bandwidths corresponds to the gamma frequency proposed, as noted previously, to be the neurobiological signature of attentional processes and sensory binding. 
I indicated above that the primary interconnectivity of the DD is with other pallial divisions. Using electric brown ghost knifefish, Elliott and Maler (2015) recorded extracellular and membrane electrical responses from DD neurons in response to electrosensory or acoustic stimulation. Extracellular recordings indicated that DD neurons respond with sustained discharge to sensory stimulation (ELLIOTT; MALER, 2015). It is interesting that the onset latency for response of DD neurons to electrosensory stimulation observed by Elliott and Maler was substantially longer than that found for lateral DM neurons in the study by Prechtl et al. (1998). This finding is compatible with the anatomical data described above that suggest that the DD functions as an associative pallial region.

The results of patch-clamp recordings (ELLIOTT; MALER, 2015) were compatible with this interpretation. In response to electrosensory stimulation DD neurons showed increased excitability which correlated with the frequency of extracellular spiking. Acoustic stimulation produced similar effects. The results of this experiment support the proposal that the DD is involved in reentrant processing of sensory input that first arrives in other pallial divisions. They also expand our knowledge of the regional complexity of the pallium and the plausibility of the proposal that fish pallium is complex enough to support sentience.

\section{BEHAVIORAL REPORTS AND SENTIENCE IN FISH}

Acknowledging the caveat given above about the limitations on generalization from a small number of species to all fish, the evidence from neuroanatomical and neurophysiological research yet supports the hypothesis that at least some fish are sentient. However, this conclusion depends upon analogic reasoning from presumed human NCCs and human NCCs rely on inference from a subject's first-person reports to a third-person observer. The observer then correlates the contents of the report with third-person observations of the subject's brain anatomy or physiology. First-person reports by humans are generally verbal in nature and are usually taken as "accurate reports" of conscious states because we have reference in our own use of language to describe our own conscious experiences. Animals can't talk so in drawing inferences about the presence and contents of conscious states we must infer accurate reports from nonverbal behaviors. Therefore, we rely upon behaviors exhibited by the animal being studied that we believe 
imply the need for consciousness in humans. In a previous section I chose to discuss one such behavior, allocentric spatial representation, because, in response to Rose's (2007; ROSE et al., 2014) request for validation, some neuroanatomical correlates of this behavior in the fish brain can be related to some neuroanatomical correlates of sentience in humans.

My argument would carry more weight if many more behaviors related to sentience in humans were described, even if their neurological foundation in fish is unknown. Space does not permit me to do that. Fortunately, I do not need to do so because several reviews have provided dozens of examples of behaviors supporting the existence of sentience in fish (BRAITHEWAITE, 2010; BROWN, 2014, 2017; SNEDDON, 2015; SNEDDON et al., 2018; WOODRUFF, 2017a). However, I do think it is useful to discuss two additional examples of behavioral abilities associated with sentience in humans that have been demonstrated in fish. These are the ability for transitive inference (TI) and the ability of a subject to recognize its own body in a mirror.

In addition to allocentric spatial navigation transitive inference (TI) provides an excellent example of a behavior associated with sentience in humans (COHEN et al., 1997; EICHENBAUM; COHEN, 2014; SMITH; SQUIRE, 2005). Thus, the presence of TI in a non-human species can be taken as an indication that the species is sentient.

TI is the ability to infer a relationship between items that have not been previously directly compared. First observing that $\mathrm{A}<\mathrm{B}, \mathrm{B}<\mathrm{C}$, and $\mathrm{C}<\mathrm{D}$, and then deducing that $\mathrm{A}<\mathrm{D}$ is an example of TI. Grosenick et al. (2007) demonstrated that male cichlid fish (Astatotiliapia burtoni) exhibit TI. Male A. burtoni fight for territory. A bystander male (BM) was placed in the center of an arena surrounded by five small compartments (A through E) with transparent walls. Each compartment housed a combatant fish (CF). CF B was introduced into CF A's compartment, then CF C into CF B's, and so on. Each invader lost the ensuing fight. For example, CF A beat CF B and CF D beat CF E. CF A and CF E were then placed in separate transparent chambers and the time the $\mathrm{BM}$ spent near each fish was recorded. This was repeated for CF B and CF D. Although CF A had not fought with CF E, nor CF B with $\mathrm{CF} \mathrm{D}$, the $\mathrm{BMs}$ consistently spent more time in the vicinity of the losers (B and E) than they did in the vicinity of winners. This is a clear indication of TI and supports the hypothesis that fish are sentient. Furthermore, because destruction of the hippocampal formation impairs TI in humans (SMITH; 
SQUIRE, 2005. The effects of DL lesions on TI in archer fish have not been demonstrated, but it is a testable hypothesis that DL lesions would impair TI.

The ability to pass the mirror test developed by Gallup (1970) in chimpanzees is often considered as an indication not just of sentience, but of self-consciousness. In a recent study (KOHDA et al., 2018) adapted the mirror test for use in cleaner wrasse fish (labroides dimidiatus). As the mirror test is generally conducted the test subject is placed in a cage, chamber, or in the case of aquatic species tank full of water without a mirror for several days. The mirror is then introduced into the enclosure and responses to it are recorded both qualitatively and quantitatively. This provides a baseline of type and frequency of mirror-directed behaviors. At the end of this baseline period the subject animal is anesthetized, and a mark or marks placed where they can only be seen in the mirror. Care is taken to control for any sensation produced by the marks on the skin. After the animal recovers from anesthesia responses to the mirror are monitored for several days. The number and type of responses to the mark are recorded. If the animal frequently responds to the mark by, in the case of chimpanzees touching it, the animal is said to have passed the test. Although this interpretation is not without controversy, many people regard the mirror or, as Kohda et al. call it, the mark test as a quantitative measure of the ability of the animals to be self-aware. Several different kinds of animals have passed this test including chimpanzees, orangutans, elephants, dolphins, crows and magpies, but far more species fail the test than pass it (refer to Kohda et al., for references). The ability to pass the test is thought to require a level of brain development and cognitive capacity not available to fish.

Cleaner wrasse feed on parasites that live on the skin of larger "client" fish. Thus, they have the visual acuity to detect small colored objects. They also demonstrate sophisticated cognitive abilities including deception, reconciliation with client fish and the ability to predict behavior of other individuals (KOHDA et al., 2018). Therefore, Kohda et al. hypothesized that the cleaner wrasse fish might have the perceptual abilities and preexisting level of cognitive ability and behavioral repertoire needed to pass the mark test.

Kohda et al. tested 10 fish. When the fish was introduced to the mirror before being marked, they went through the three phases of behavior often reported for mammals and birds. The first was social reaction towards the mirror. The second was repetitive performance of odd behaviors rarely observed in the absence of the mirror. For example, a fish would swim upside- 
down toward the mirror. Kohda et al. interpreted these behaviors to represent contingency testing between the actions of the subject and the behavior of its reflection. In the third phase the fish would "gaze and examine" its reflection without aggressive or mirror-testing behaviour. If a fish passed all three phases colored marks were placed on the lateral body surface or throat area, places that could not be seen without the mirror. Controls for the effects of cutaneous stimulation were also introduced. The fish responded to the marks in two ways. They assumed postures that would allow them to see the mark and they would then scrape the part of the body on a surface. Scraping did not occur in absence of the marks. Kohda et al. interpreted scraping to indicate that the fish reacted to the mark as if it was a skin parasite and used the mirror for removal efforts directed toward its own body.

So, cleaner wrasse can pass the mark test. But what does this mean? Do they recognize themselves in the mirror in the same way that human being? That would seem to mean they have a robust point of view and higher order consciousness. Recognizing the caveat that we can't know what the sentience of cleaner wrasse fish is like it still seems highly unlikely that they recognize themselves. However, I do think that this experiment supports the argument they are sentient. Furthermore, I believe the results of this experiment are very compatible with Vellman's reflexive model of perceptual consciousness. Indeed, it indicates that brain of the cleaner wrasse the fish not only has the capability of neural activity representing the external environment and projecting that representation out into space, but that its brain can make the projection in the appropriate direction, i.e. back towards its body surface once it has formed an enduring representative image of that surface through exposure to a mirror. Thus, although the cleaner wrasse fish lacks a robust first-person perspective and what Pereira Jr. refers to as conceptual consciousness, reflexive perceptual mechanisms support a rudimentary first-person perspective and nonconceptual sentience that enable it to pass the mark (mirror) test.

\section{Conclusion}

In this paper I first developed an argument that Velmans' model of reflexive perceptual consciousness resolves the apparent difficulties with using the first-person perspective in the scientific study of consciousness. I supported this argument in part by turning to Kuhn's analysis in which he questions the absolute objectivity of the third-person perspective. I think that this is a useful 
move because it employs an approach which differs from, and supplements, Velmens' to bring the first- and third-person points of view closer together as valid perspectives from which to conduct scientific research. I then advocated that Velman's reflexive monism is not only useful in providing a philosophical framework for studying consciousness in humans, but that it is useful as a framework for studying consciousness in animals, specifically sentience in fish.

One objection I can think of to this last claim is that, as the reflexive model of perceptual consciousness is applied to humans, there is the ability, based on similarities in neural and cognitive structure and the availability of verbal communication, for the experimenter and the subject to literally change places. Hence, although we cannot know by direct experience what another person's conscious states contain or feel like, there is a high probability that a consensus can be reached that what he or she describes as the contents and feel of those states is an accurate report (PRICE; BARRELL, 2012; VELMANS, 2007, 2009, 2012). Because of the vast distance between humans and fish along the branches of the phylogenetic tree, it is impossible to reach a consensus with a fish as to what its rudimentary subjective firstperson perspective on its sentient states contains and how it feels. We can only infer that fish have some type of consciousness from the behaviors they exhibit and structure of their brains.

The usefulness of Velman's model, then, comes once it can be demonstrated that fish have a first-person perspective from which to initiate reflexive perceptual consciousness. I described abilities possessed by fish which I believe, mixing concepts from Baker (2013) and Pereira Jr. (2018), clearly indicate that fish have a non-conceptual, rudimentary first-person perspective. These are egocentric and allocentric spatial representation and the ability to respond to their own images in a mirror. In each of these cases the brain of the animal must have the capacity to accurately represent the environment. Indeed, egocentric spatial representation may be a pure example of Velmens' model. An object in the environment affects the sensory system of the fish causing a representation of that object in the fish's brain. The fish's in turn projects that representation to physical location of that object in the environment (as inferred from adaptive behavioral responses to the object).

I argued above that egocentric spatial behavior indicates the presence of a rudimentary first-person perspective and what Pereira Jr. (2018) names an extended conscious domain (ECD). Allocentric spatial representation and the ability to relate a reflection in a mirror to egocentric space require 
relational learning among stimuli distributed in space, over time, or both. This ability for relational learning seems to exceed the basic requirements for ECD and their presence suggests that sentience in fish indeed enables significant flexibility and behavior.

I also devoted space to arguing that the fish pallium provides an important substrate for sentience in fish. I presented evidence that the fish brain is sufficiently complex to support sentience as I defined it in this article. I paid particular attention to the organization of the pallium and to its anatomical relationship the preglomerular complex. I drew attention to the similarities, albeit they are slight, between the anatomical organization of the pallium and its relationship to the $\mathrm{PgC}$ and the organization of the mammalian neocortex and thalamus. I also related this organization of the fish brain to allocentric representation and memory. I ended the section on fish neurobiology with a description of several electrophysiological NCCs found in fish.

I conclude, then, that the neuroanatomical and neurophysiological data support the hypothesis that the fish brain is complex enough to produce a rudimentary first-person perspective and sentience. That written, I must note that many, probably even most, of the neuroanatomical and neurophysiological NCCs proposed for human consciousness are not found in the fish brain. However, even with the vast differences between the neurobiology of fish and humans, certain basic principles seem to maintain although they are instantiated differently. These include, for example, relationships between first-, second-, and third-order sensory relays, feedforward/feedback and reentry circuitry, and neural modulatory pathways that influence affective tone and motivational states. Philosophically this is an important point as it implies a functionalist position. To quote Braithwaite and Droege (2016), when evaluating the presence or absent of sentience "the question is not whether fish have a cortex or an insula, but whether they have the functional capacity for (indicators of consciousness such as) global integration and attentional amplification."

WOODRUFF, M. L. O peixe no riacho é sentiente, mesmo que eu não possa falar com ele. Trans/Form/Ação, Marília, v. 41, p. 119-152, 2018. Edição Especial. 
Resumo: Neste artigo, argumento que o modelo reflexivo de consciência perceptiva de Velmans é útil para se entender a perspectiva de primeira pessoa e a sentiência em animais. Em seguida, ofereço uma defesa da proposta de que os peixes ósseos com nadadeiras raiadas tenham sentiência e perspectiva de primeira pessoa. Esta defesa tem dois momentos. O primeiro ponto é a presença de um corpo substancial de evidências de que a neuroanatomia do cérebro de peixes exibe os princípios organizacionais básicos associados à consciência em mamíferos. Esses princípios incluem a interaçáo entre um relê sensorial de segunda ordem (o complexo pré-glomerular) e o pálio, os quais apresentam, respectivamente, estreita semelhança com o tálamo e o neocórtex dos mamíferos; a existência de circuitos de retroalimentação e reentrada, assim como diferenças estruturais e funcionais entre as divisóes do pálio. A segunda questão é a existência de comportamentos de peixes que exibem flexibilidade significativa na presença de mudanças ambientais e requerem aprendizado relacional entre estímulos distribuídos no espaço, ao longo do tempo, ou ambos. Concluo que, embora sejam instanciados de maneira diferente dos mamíferos, uma perspectiva de primeira pessoa e sentiência estấo presentes nos peixes.

Palavras-Chave: Sentiência. Peixe. Comportamento. Pálio. Monismo reflexivo.

\section{REFERENCES}

AGGLETON, J P. et al. Hippocampal-anterior thalamic pathways for memory: uncovering a network of direct and indirect actions. European Journal of Neuroscience, v. 31, n. 12, p. 2292-2307, 2010.

ALLEN, Colin; TRESTMAN, Michael. Animal consciousness. In: ZALTA, E. N. (ed.). The Stanford Encyclopedia of Philosophy. Winter Edition. 2016. Available on: <https:// plato.stanford.edu/archives/win2016/entries/consciousness-animal/>. Access in: 1o jul. 2018.

ALLEN-HERMANSON, S. Battlefish contention. Animal Sentience, v. 13, n. 3, 2017.

ANDREWS, K. Animal minds: an introduction to the philosophy of animal cognition. New York, NY: Routledge, 2015.

BAARS, B. J.; LAUREYS, S. One, not two, neural correlates of consciousness. Trends in Cognitive Sciences, v. 9, n. 6, p. 269, 2005.

BAKER, L. R. Cognitive suicide. In: GRIMM, R. H.; MERRILL, D. D. (ed.). Contents of thought. Tucson, AZ: University of Arizona Press, 1988. p. 401-413.

Press, 2013.

Naturalism and the first-person perspective. New York, NY: Oxford University

BINGMAN, V. P.; RODRÍGUEZ, F.; SALAS, C. The hippocampus of nonmammalian vertebrates. In: KAAS, J. (ed.). Evolution of nervous systems. 2nd ed., v. 1. Oxford, UK: Elsevier, 2017. p. 479-489.

BIRCH, J. Animal sentience and the precautionary principle. Animal Sentience, v. 16, n. $1,2017$.

BLOCK, N. On a confusion about a function of consciousness. Behavioral and Brain Sciences, v. 18, p. 227-287, 1995. 
BOLY, M. et al. Are the neural correlates of consciousness in the front or in the back of the cerebral cortex? Clinical and neuroimaging evidence. The Journal of Neuroscience, v. 37, n, 40, p. 9603-9613, Oct. 2017.

BOLY, M. et al. Consciousness in humans and non-human animals: recent advances and future directions. Frontiers in Psychology, v. 4, p. 625, 2013. doi: 10.3389/ fpsyg.2013.00625.

BRAITHWAITE, V. A. Do fish feel pain? Oxford, UK: Oxford University Press, 2010. .; DROEGE, P. Why human pain can't tell us whether fish feel pain. Animal Sentience, v. 3, n. 3, 2016.

BREMNER, J. Gavin Egocentric versus allocentric spatial coding in nine-month-old infants: factors influencing the choice of code. Developmental Psychology, v. 14, n. 4, p. 346-355, 1978.

BROWN, C. Fish intelligence, sentience and ethics. Animal Cognition, v. 18, n. 1, p. $1-17,2014$.

A risk assessment and phylogenetic approach. Animal Sentience, v. 16, n. 3, 2017.

CABANAC, M.; CABANAC, A. J.; PARENT A. The emergence of consciousness in phylogeny. Behavioural Brain Research, v. 198, n. 2, p. 267-272, 2009.

CANFIELD, J. G.; MIZUMORI, S. J. Y. Methods for chronic neural recording in the telencephalon of freely behaving fish. Journal of Neuroscience Methods, v. 133, n. 1/2, p. 127-134, 2004.

CARRUTHERS, P. Brute experience. The Journal of Philosophy, v. 86, n. 5, p. 258-269, 1989.

CHURCHLAND, P. M. Eliminative materialism and the propositional attitudes. Journal of Philosophy, v. 78, n. 2, p. 67-90, 1981.

CHURCHLAND, P. S. Neurophilosophy: toward a unified science of the mind/brain. Cambridge, MA: MIT Press, 1986.

COHEN, N. J.; POLDARK; R. A.; EICHENBAUM, H. Memory for items and memory for relations in the procedural/declarative memory framework. Memory, v. 5, n. 1-2, p. 131-178, 1997.

CRESON, T. K. et al. Dose response effects of chronic lithium regimen on spatial memory in the black molly fish. Pharmacology, Biochemistry and Behavior, v. 75, n. 1, p. 35-47, 2003.

CRICK, F. The astonishing hypothesis: the scientific search for the soul. New York, NY: Touchstone/Simon and Schuster, 1994. .; KOCH, C. A framework for consciousness. Nature Neuroscience, v. 6, n. 2, p. 119-126, 2003. 
DAMASIO, A. R. Self comes to mind: constructing the conscious mind. New York, NY: Pantheon Books, 2010.

DEHAENE, S. Consciousness and the brain: deciphering how the brain codes our thoughts. New York, NY: Penguin, 2014.

DEMSKI, L. S. The pallium and mind/behavior relationships in teleost fishes. Brain Behavior and Evolution, v. 82, n. 1, p. 31-44, 2013.

DENNETT, D. Consciousness explained. Boston, MA: Back Bay Books; Little Brown, 1991.

DOUGLAS, H. Science, policy, and the value-free ideal. Pittsburgh, PA: University of Pittsburgh Press, 2009.

DRETSKE, F. Naturalizing the mind. Cambridge, MA: MIT Press, 1995.

DURÀN, E. et al. Lateral but not medial telencephalic pallium ablation impairs the use of goldfish spatial allocentric strategies in a "hole-board" task. Behavioural Brain Research, v. 214 , n. 1 , p. $480-487,2010$.

ECHTELER, S. M.; SAIDEL, W. M. Forebrain connections in the goldfish support telencephalic homologies with land vertebrates. Science, v. 212, n. 4495, p. 683-685, 1981.

EDELMAN, D. B.; SETH, A.K. Animal consciousness: a synthetic approach. Trends in Neuroscience. v. 32, n. 9, p. 476-484, 2009.

.: BAARS, B. J.; SETH, A. K. Identifying hallmarks of consciousness in nonmammalian species. Consciousness and Cognition, v. 14, n. 1, p. 169-187, 2005.

EDELMAN, G. M. The remembered present: a biological theory of consciousness. New York, NY: Basic Books. 1989.

. Naturalizing consciousness: a theoretical framework. Proceedings of the National Academy of Sciences USA, v. 100, n. 9, p. 5520-5524, 2003.

EICHENBAUM, H. A cortical-hippocampal system for declarative memory. Nature Reviews Neuroscience, v. 1, n. 1, p. 41-50, 2000.

.; COHEN, N. J. Can we reconcile the declarative memory and spatial navigation views on hippocampal function? Neuron, v. 83, n. 4, p. 764-770, 2014.

EKSTROM, A. D.; ARNOLD, A. E. G. F.; IARIA, G. A critical review of the allocentric spatial representation and its neural underpinnings: toward a network-based perspective. Frontiers in Human Neuroscience, v. 9, p. 803, 2014. doi: 10.3389/fnhum.2014.00803

ELLIOTT, S. B.; MALEER, L. Stimulus-induced up states in the dorsal pallium of a weakly electric fish. Journal of Neurophysiology, v. 114, n. 3, p. 2071-2076, 2015.

FEINBERG, T. E.; MALLATT, J. M. The ancient origins of consciousness: how the brain created experience. Cambridge, MA: MIT Press, 2016. 
GALLUP JR., G. G. Chimpanzees: self-recognition. Science, v. 167, n. 3914, p.86-87, 1970.

GENNARO, R. Higher-order thoughts, animal consciousness, and misrepresentation: a reply to Carruthers and Levine. In: . (ed.). Higher-order theories of consciousness: an anthology. Amsterdam: John Benjamins, 2004.

GENNARO, R. J.; FISHMAN, Y. I. The argument from brain damage vindicated. In: AUGUSTINE, K.; MARTIN, M. (ed.). The myth of an afterlife: the case against life after death. Lanham, MD: Rowman \& Littlefield, 2015. p. 105-133.

GIASSI, A. C. C.; ELLIS, W.; MALER, L. Organization of the gymnotiform fish pallium in relation to learning and memory: III. Intrinsic connections. Journal of Comparative Neurology, v. 520, n 15, p. 3369-3394, 2012a.

GIASSI, A. C. C. et al. Organization of the gymnotiform fish pallium in relation to learning and memory: I. Cytoarchitectonics and cellular morphology. Journal of Comparative Neurology, v. 520, n. 15, p. 3314-3337, 2012 b.

GROSENICK, L.; CLEMENT, T. S.; FERNALD, R. D. Fish can infer social rank by observation alone. Nature, v. 445, p. 429-432, 2007.

HAACK, S. Science within reason: between scientism and cynicism. Amherst, NY: Prometheus Books, 2007.

HARKER, D. Creating scientific controversies: uncertainty and bias in science and society. Cambridge: Cambridge University Press, 2015.

HAYNES, J.-D.; DRIVER, J.; REES, G. Visibility reflects dynamic changes of effective connectivity between V1 and fusiform cortex. Neuron, v. 46, n. 5, p. 811-821, 2005.

ITO, H. et al. Thalamic fiber connections in a teleost (Sebastiscus marmoratus): visual somatosensory, octavolateral, and cerebellar relay region to the telencephalon. Journal of Comparative Neurology, v. 250, n. 2, p. 215-227, 1986.

JANKOWSKI, M. et al. The anterior thalamus provides a subcortical circuit supporting memory and spatial navigation. Frontiers in Systems Neuroscience, v. 7, p. 45, Aug. 2013. doi:10.3389/fnsys.2013.00045.

KARTEN, H. J. Vertebrate brains and evolutionary connectomics: on the origins of the mammalian 'neocortex'. Philosophical Transactions of the Royal Society of London B: Biological Sciences, v. 370, n. 1684, 2015. doi: 10.1098/rstb.2015.0060.

KASKAN, P. M. et al. Intrinsic-signal optical imaging reveals cryptic ocular dominance columns in primary visual cortex of New World owl monkeys. Frontiers in Neuroscience, v. 1, n. 1, p. 67-75, 2007.

KEY, B. Fish do not feel pain and its implications for understanding phenomenal consciousness. Biology and Philosophy, v. 30, n.2, p. 149-165, 2015.

. Why fish do not feel pain. Animal Sentience, v. 3, n. 1, 2016. 
KEY, B. et al. Problems with equating thermal preference with 'emotional fever' and sentience: comment on 'Fish can show emotional fever: stress-induced hyperthermia in zebrafish' by Rey et al. (2015). Proceedings of the Royal Society, B, v. 284, n. 1847, 2017. doi:10.1098/rspb.2016.0681.

$\mathrm{KOCH}, \mathrm{C}$. Consciousness: confessions of a romantic reductionist. Cambridge, MA: The MIT Press, 2012.

KOHDA, M. et al . Cleaner wrasse pass the mark test: what are the implications for consciousness and self-awareness testing in animals? BioRxiv, 2018. doi: https://doi. $\operatorname{org} / 10.1101 / 397067$.

KUHN, T. S. The structure of scientific revolutions. 2nd ed. enlarg. Chicago, IL: University of Chicago Press, 1970.

LAMBOOJI, B. et al. Electrophysiological and behavioural responses of turbot (Scophthalmus maximus) cooled in ice water. Physiology and Behavior, v. 149, p. 23-28, 2015. doi:10.1016/j.physbeh.2015.05.019.

LAMBOOJI, E. et al. Percussion and electrical stunning of Atlantic salmon (Salmo salar) after dewatering and subsequent effect on brain and heart activities. Aquaculture, v. 300, n. 1/4, p. 107-112, 2010.

LAMBOOJI, E. et al. Assessment of electrical stunning in fresh water of African catfish (Clarias gariepinus) and chilling in ice water for loss of consciousness and sensibility. Aquaculture, v. 254, n. 1/4, p. 388-395, 2006.

LEVINE, J. Materialism and qualia: the explanatory gap. Pacific Philosophical Quarterly, v. 64, p. 354-361, 1983.

LEWIS, D. Mad pain and Martian pain. In: BLOCK, N. (ed.). Readings in the philosophy of psychology. Cambridge, MA: Harvard University Press, 1980. p. 216-222.

LLINÀS, R. et al. The neuronal basis for consciousness. Philosophical Transactions of the Royal Society B Biological Sciences, v. 353, n. 1377, p. 1841-1849, 1998. doi: 10.1098/ rstb.1998.0336.

MERKER, B. Consciousness without a cerebral cortex: a challenge for neuroscience and medicine. Behavioral and Brain Sciences, v. 30, n.1, p. 63-81, 2007.

MUELLER, T. What is the thalamus in zebrafish? Frontiers in Neuroscience, v. 64, n. 1, 2012. doi: 10.3389/fnins.2012.00064.

NADEL, L. The hippocampus and space revisited. Hippocampus, v. 1, n. 3, p. 221-229, 1991

NAGEL, T. What is it like to be a bat? The Philosophical Review, v. 83, n. 4, p. 435-450, 1974.

The view from nowhere. Oxford: Oxford University Press, 1986. 
NIEUWENHUYS, R.; MEEK, J. The telencephalon of actinopterygian fishes. In: JONES, Edward G.; PETERS, A. (ed.). Comparative structure and evolution of the cerebral cortex. New York, NY: Plenum, 1990. p. 31-73.

NILSSON, J. et al. Learning in cod (Gadus morhua): long trace interval retention. Animal Cognition, v. 11, n. 2, p. 215-222, 2008.

NILSSON, J. et al. Learning and anticipatory behaviour in a "sit-and-wait" predator: the Atlantic halibut. Behavioral Processes, v. 83, n. 3, p. 257-266, 2010.

NORTHCUTT, R. G. Connections of the lateral and medial divisions of the goldfish telencephalic pallium. Journal of Comparative Neurology, v. 494, n. 6, p. 903-943, 2006.

OCAÑA, F. M. et al. Dynamics of goldfish subregional hippocampal pallium activity throughout spatial memory formation. Brain Behavior and Evolution, v. 90, p.154-170, 2017.

O'KEEFE, J.; NADEL, L. The hippocampus as a cognitive map. Oxford, UK: Oxford University Press, 1978.

ORPWOOD, R. Qualia could arise from information processing in local cortical networks. Frontiers in Psychology, v. 4, n. 121, 2013. doi: 10.3389/fpsyg.2013.00121.

OTEIZA, P. et al. A novel mechanism for mechanosensory based rheotaxis in larval zebrafish. Nature, v. 547, n. 7664, p. 445-448, 2017.

PANKSEPP, J. Affective consciousness: core emotional feelings in animals and humans. Consciousness and Cognition, v. 14, n. 1, p. 30-80, 2005.

PEREIRA JR., A. Triple-aspect monism: a conceptual framework for the science of human consciousness. In: PEREIRA JR., A.; LEHMANN, D. (ed.). The unity of mind, brain and world: current perspectives on a science of consciousness. Cambridge, UK: Cambridge University Press, 2013. p. 299-337.

. Triple-aspect monism: Physiological, mental unconscious and conscious aspects of brain activity. Journal of Integrative Neuroscience, v. 13, n. 2, p. 1-27, 2014.

. The projective theory of consciousness: from neuroscience to philosophical psychology. Trans/Form/Ação, v. 41, n. especial, 2018, p. 199-232.

PORTAVELLA, M.; TORRES, B.; SALAS, C. Avoidance response in goldfish: emotional and temporal involvement of medial and lateral telencephalic pallium. The Journal of Neuroscience, v. 24, n. 9, p. 2335-2342, 2004.

PRECHTL, J. C. et al. Sensory processing in the pallium of a mormyrid fish. Journal of Neuroscience, v. 18, n. 18, p. 7381-7393, 1998.

PRICE, D. D.; BARRELL, J. J. Inner experience and neuroscience: merging both perspectives, Cambridge, MA: MIT Press, 2012.

ROSE, J. D. The neurobehavioral nature of fishes and the question of awareness and pain. Reviews in Fisheries Science, v. 10, n. 1, p. 1-38, 2002. 
. Anthropomorphism and 'mental welfare' of fishes. Diseases of Aquatic Organisms, v. 75, n. 2, p. 139-154, 2007.

ROSE, J. D. et al. Can fish really feel pain? Fish and Fisheries, v. 15, n. 1, p. 97-133, 2014.

ROSENTHAL, D. M. Consciousness and mind. New York: Oxford University Press, 2005.

SEARLE, J. R. Consciousness. Annual Review of Neuroscience. v. 23, p. 557-578, 2000.

SETH, A.; BAARS, B. J.; EDELMAN, D. B. Criteria for consciousness in humans and other mammals. Consciousness and Cognition, v. 14, n. 1, p. 119-139, 2005.

SMART, John J. C. Sensations and brain processes, Philosophical Review, v. 68, n. 2, p. $141-156,1959$.

SMITH, C.; SQUIRE, L. R. Declarative memory, awareness, and transitive inference. Journal of Neuroscience, v. 25, n. 44, p. 10138-10146, 2005.

SNEDDON, L. U. Pain in aquatic animals. Journal of Experimental Biology, v. 218, p. 967-976, 2015.

SNEDDON, L. U. et al. Fish sentience denial: muddying the waters. Animal Sentience, v. $115,2018$.

SPERRY, R. W. In defense of mentalism and emergent interaction. The Journal of Mind and Behavior, v. 12, n. 2, p. 221-246, 1991.

STRAKA, H.; BAKER, R. Vestibular blueprint in early vertebrates. Frontiers in Neural Circuits, v. 7, p. 182, 2013. doi: 10.3389/fncir.2013.00182.

TRINH, A.-T. et al. Cryptic laminar and columnar organization in the dorsolateral pallium of a weakly electric fish. Journal of Comparative Neurology, v. 524, n. 2, p. 408428, 2015.

TYE, M. Consciousness, color, and content. Cambridge, MA: MIT Press, 2000.

UCEDA, S. et al. Spatial learning-related changes in metabolic brain activity contribute to the delimitation of the hippocampal pallium in goldfish. Behavioral Brain Research, v. 292, p. 403-408, 2015.

VARGAS, J. P. et al. Telencephalon and geometric space in goldfish. European Journal of Neuroscience, v. 24, n. 10, p. 2870-2878, 2006.

VARGAS, J. P.; LÖPEZ, J. C.; PORTAVELLA, M. What are the functions of fish brain pallium? Brain Research Bulletin, v.79, n. 6, p. 436-440, 2009.

VARGAS, R.; THORSTEINSSON, H.; KARLSON, K. A. Spontaneous neural activity of the anterodorsal lobe and entopeduncular nucleus in adult zebrafish: a putative homologue of hippocampal sharp waves. Behavioral Brain Research, v. 229, n. 1, p. 10-20, 2012. 
VELMANS, M. An epistemology for the study of consciousness. In:

SCHNEIDER, S. (ed.). The Blackwell companion to consciousness. New York, NY: Blackwell, 2007. p. 711-725.

. Understanding consciousness. 2nd ed. London: Routledge, 2009.

. Reflexive monism: psychophysical relations among mind, matter and consciousness. Journal of Consciousness Studies Special Issue on Monist Alternatives to Physicalism, v. 19, n. 9-10, p. 143-165, 2012.

WALLACH, A. et al. A novel time-stamp mechanism transforms egocentric encounters into an allocentric spatial representation. BioRxiv, 2018. doi: https://doi. org/10.1101/285494.

WHITE, G. E.; BROWN, C. Cue choice and spatial learning ability are affected by habitat complexity in intertidal gobies. Behavioral Ecology, v. 26, n. 1, p. 178-184, 2015.

WIMSATT, W. C. Reductionism, levels of organization and the mind-body problem. In: GLOBUS, G. G.; MAXWELL, G.; SAVODNIK, I. (ed.). Consciousness and the brain. New York, NY: Plenum, 1976. p. 199-267.

WOODRUFF, M. L. Consciousness in teleosts: there is something it feels like to be a fish. Animal Sentience, v. 13, n.1, 2017a.

. Scientific uncertainty and the animal sentience precautionary principle: commentary on Birch on "Animal Sentience and the precautionary principle." Animal Sentience, v. 16, n. 11, 2017b.

Sentience in fishes: more on the evidence. Animal Sentience, v. 13, n. 16, 2018.

Recebido: $15 / 11 / 2018$

Aceito: $15 / 11 / 2018$ 
WOODRUFF, M. L. 